\title{
Estados de conservação
}

\section{Cláudia Tavares ${ }^{1}$}

\section{Técnica: fotografia}

Dimensões: $120 \times 40 \mathrm{~cm}$ e $40 \times 53 \mathrm{~cm}$

Descrição: Estados de Conservação é uma série de dípticos fotográficos.

Durante a travessia de uma única estrada, no estado de Minas Gerais em 2016, o cenário vai se modificando e descortinando um panorama de assombro. Montanhas são fatiadas pela mineração, há longas extensões de plantação de eucalipto, morros estão desmatados pela atividade pecuarista.

Estado, aqui, aponta para um estar em mudança, no qual, a cada momento, pode haver uma variação de condição. Conservar remete a ideia de reter memória, conter no tempo, de estabelecer um limiar entre vida e morte, continuidade e fim.

1 Claudia Tavares é Doutora em Processos Artísticos Contemporâneos pelo Instituto de Artes UERJ, Mestra em Artes pela Goldsmiths College, Londres e em Linguagens Visuais pela Escola de Belas Artes, UFRJ e formada em Comunicação Social pela FACHA, Rio de Janeiro. Como artista visual, utiliza principalmente as linguagens da fotografia e do vídeo, em diálogo com desenhos, objetos e cadernos de artista. Ganhou o Prêmio Chico Albuquerque de Fotografia, da Secretaria de Cultura do Ceará, em 2019, com o trabalho Um jardim em Floresta, que foi base para sua tese de doutorado. E-mail: claudia@claudiatavares.com. ORCID: https://orcid.org/0000-0002-6724-3061. Lattes iD: http://lattes. cnpq.br/9972740292201303. Rio de Janeiro, Brasil 


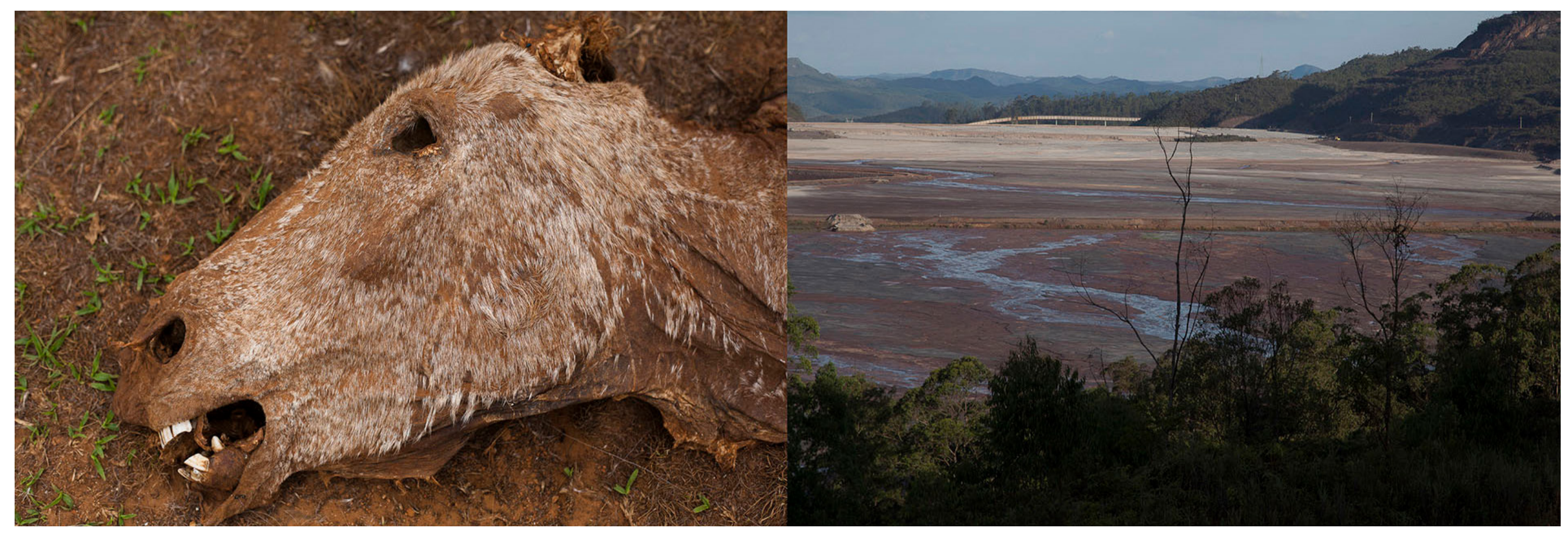




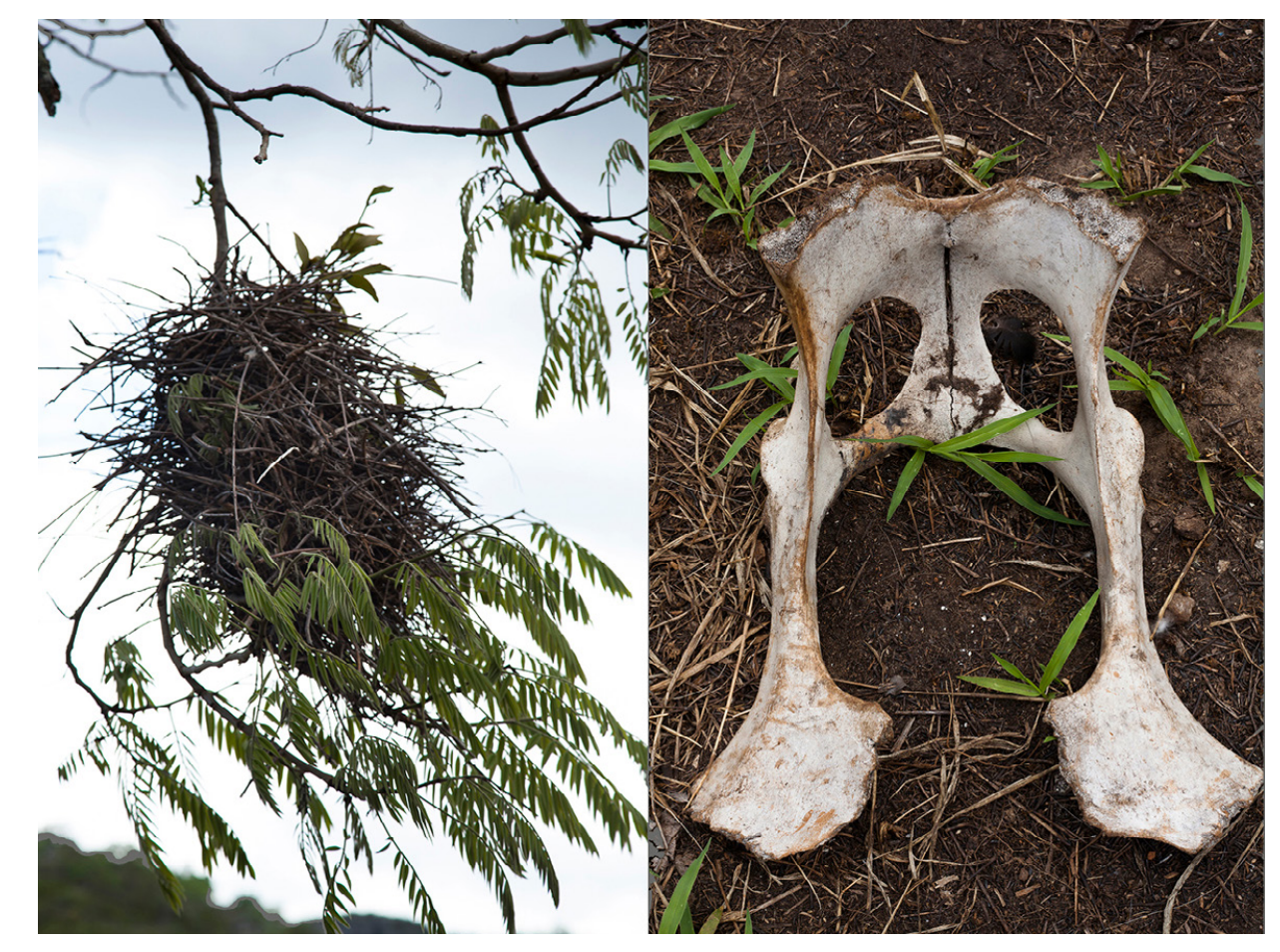




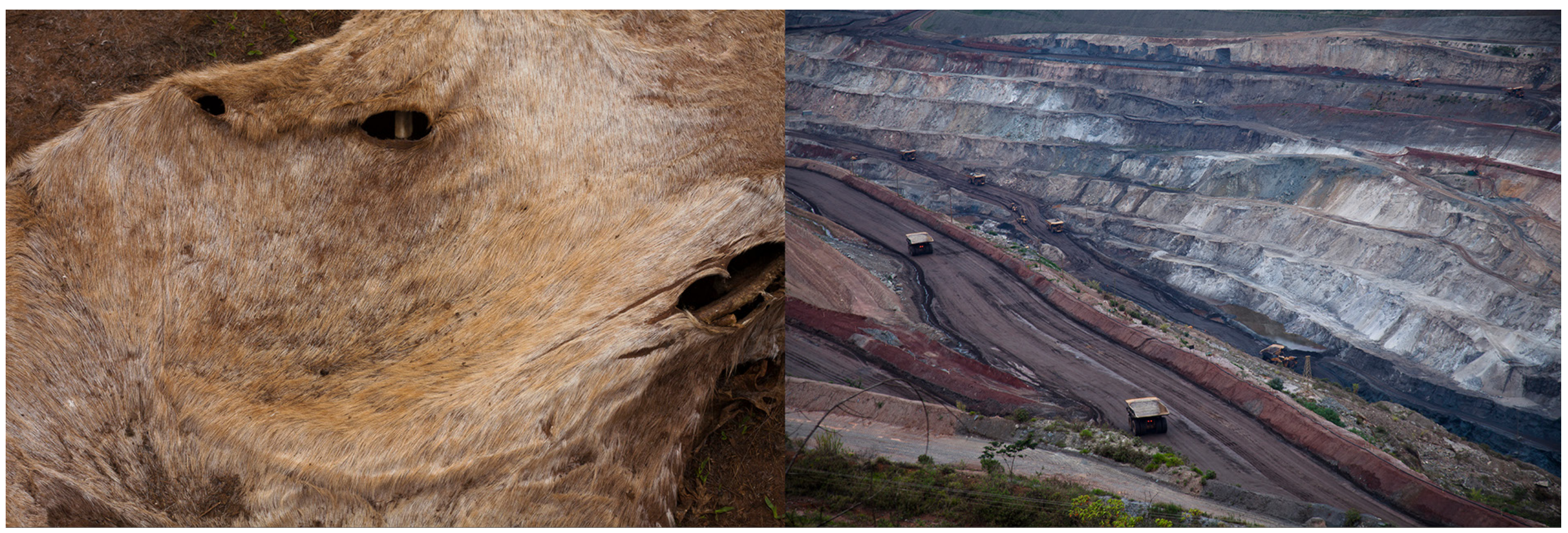




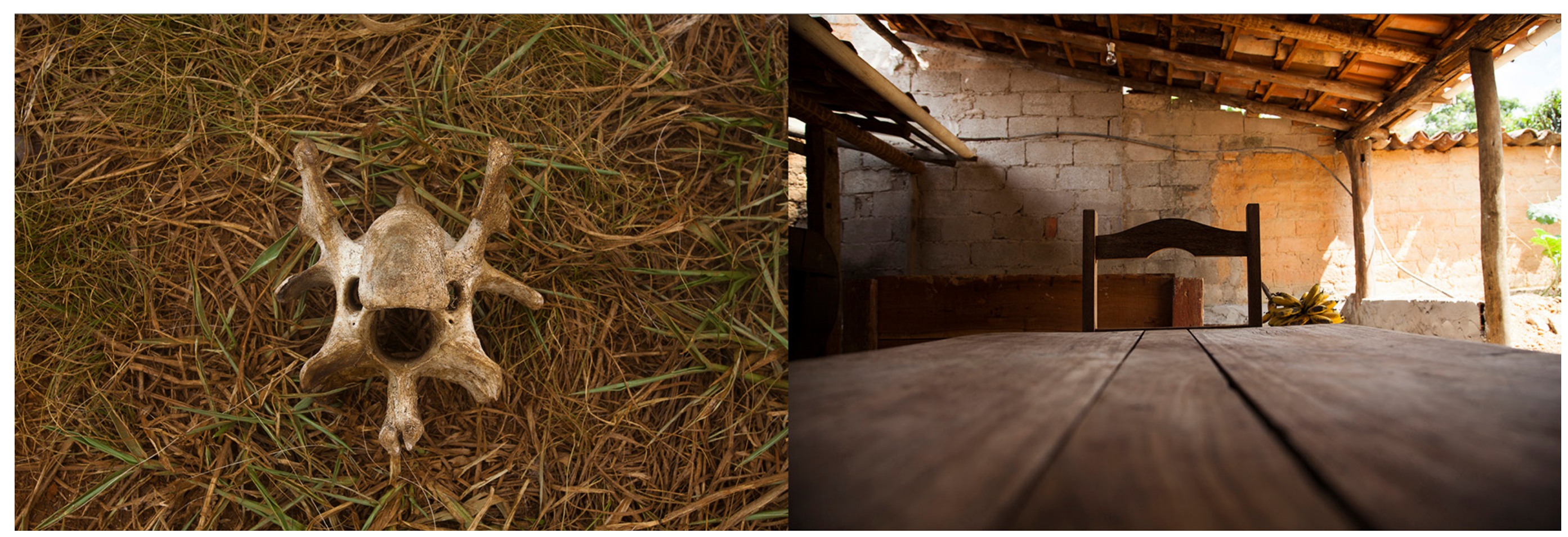




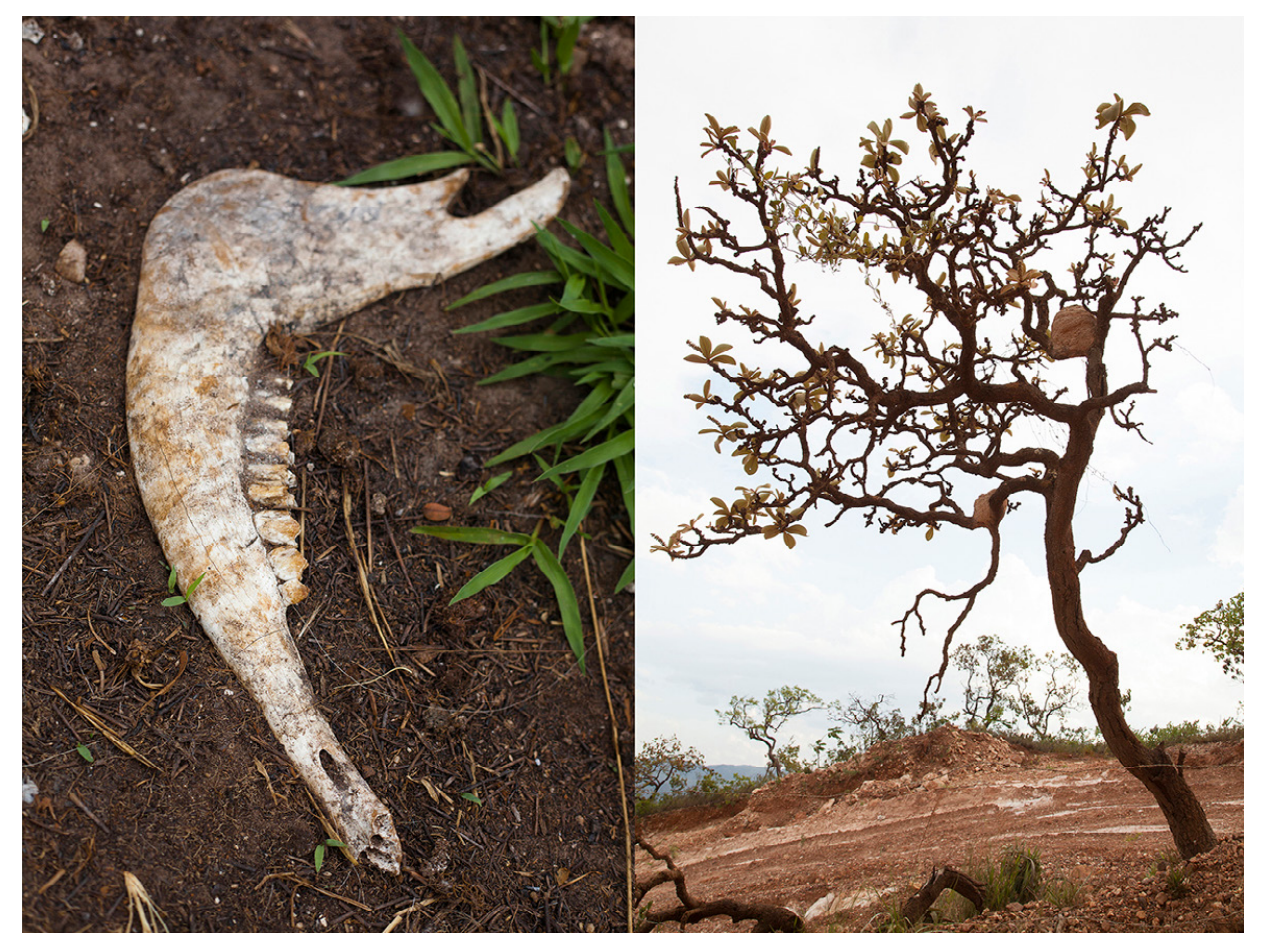




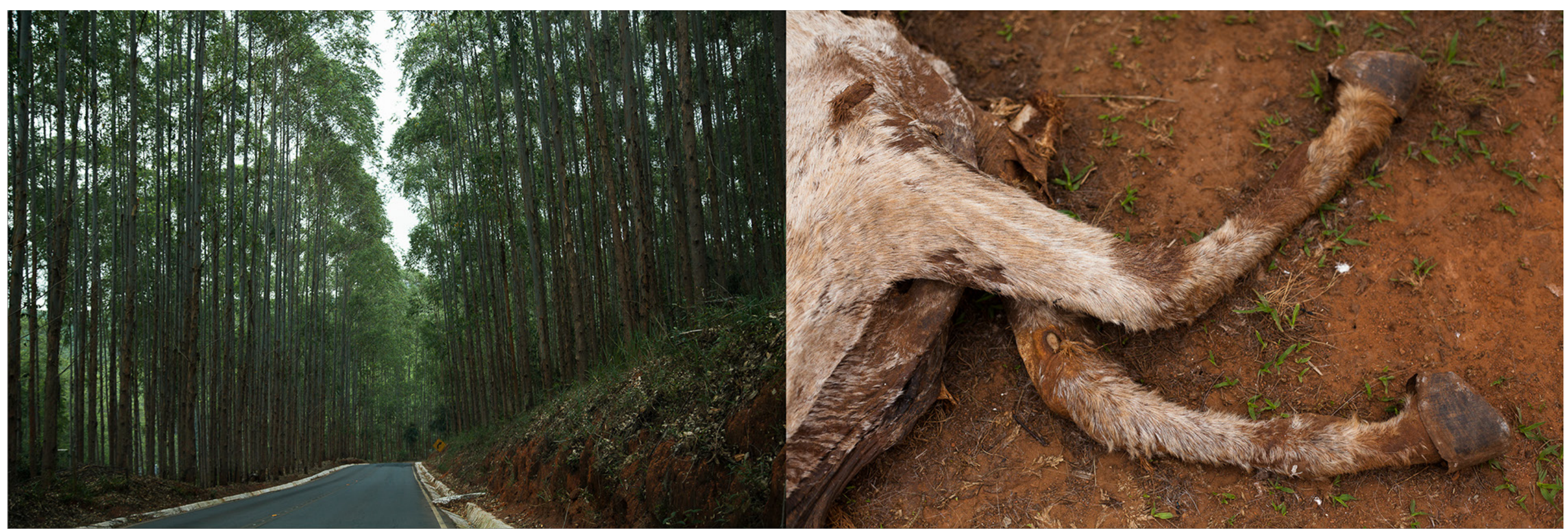


Recebido em 13 de abril de 2020 e aceito em 16 de junho de 2020 . Este é um artigo publicado em acesso aberto sob uma licença Creative Commons $(\mathbf{c c}) \mathbf{E Y}$ 